\title{
Association between health-service use and multiplex genetic testing
}

\author{
Robert J. Reid, MD, PhD'1, Colleen M. McBride, PhD², Sharon Hensley Alford, PhD, \\ Cristofer Price, $\mathrm{ScM}^{4}$, Andreas D. Baxevanis, $\mathrm{PhD}^{5}$, Lawrence C. Brody, PhD ${ }^{5}$ \\ and Eric B. Larson, MD, MPH ${ }^{1}$
}

\begin{abstract}
Purpose: The objective of this work was to examine whether offers of multiplex genetic testing increase health-care utilization among healthy patients aged $25-40$ years. The identification of genetic variants associated with common disease is accelerating rapidly. "Multiplex tests" that give individuals feedback on large panels of genetic variants have proliferated. Availability of these test results may prompt consumers to use more health-care services.
\end{abstract}

Methods: A total of 1,599 continuously insured adults aged 25-40 years were surveyed and offered a multiplex genetic susceptibility test for eight common health conditions. Health-care utilization from automated records was compared in 12-month pre- and posttest periods among persons who completed a baseline survey only (68.7\%), those who visited a study website but opted not to test (17.8\%), and those who chose the multiplex genetic susceptibility test (13.6\%).

Results: In the pretest period, persons choosing genetic testing used an average of 1.02 physician visits per quarter as compared with

\section{INTRODUCTION}

The past five years have witnessed a rapid emergence of new genetic susceptibility tests marketed directly to consumers. ${ }^{1}$ As compared with the earlier generation of single-gene tests (e.g., $B R C A 1$ and $B R C A 2$ ), the latest tests, sometimes referred to as "multiplex tests," comprise a panel of genetic assays for variants associated with common health conditions and traits. Although these genetic susceptibility tests have yet to show clinical utility, it is believed that health-care providers could eventually use these tests to motivate at-risk patients to adhere to clinical recommendations and take actions to reduce personal risk. ${ }^{2,3}$ Alternatively, concerns have been raised that such testing could inappropriately increase demand for health services by emboldening patients to request, and prompting primary care providers to order, unnecessary or inappropriate screening tests, procedures, and referrals. ${ }^{1,4}$

Indeed, there is considerable evidence to suggest that patient demand, often prompted by direct-to-consumer marketing, has significant influence on providers' referral and prescribing patterns. For instance, Mintzes and colleagues ${ }^{5,6}$ found that
0.93 and 0.82 for the baseline-only and Web-only groups, respectively $(P<0.05)$. There were no statistically significant differences by group in the pretest use of any common medical tests or procedures associated with four common health conditions. When changes in physician and medical test/procedure use in the posttest period were compared among the groups, no statistically significant differences were observed for any utilization category.

Conclusions: Persons offered and completing multiplex genetic susceptibility testing used more physician visits before testing, but testing was not associated with subsequent changes in use. This study supports the supposition that multiplex genetic testing offers can be provided directly to the patients in such a way that use of health services is not inappropriately increased.

Genet Med 2012:14(10):852-859

Key Words: delivery of health care; genetic counseling; genetic susceptibility; genetic testing

direct-to-consumer marketing prompted patients to request (and physicians to prescribe) advertised medications. ${ }^{7}$ However, little or no data are currently available to determine the specific impacts of genetic susceptibility testing on the general use of health services. There is some evidence that individuals who consider genetic testing believe that they would discuss results indicative of increased risk with physicians and that physicians have a professional responsibility to assist them in interpreting the results. ${ }^{8}$ One study, however, suggests that fewer people reported discussing personalized genomic test results with their doctors than has been anticipated. ${ }^{9}$ Even so, such testing could create new counseling demands for primary-care clinicians and empower patients to request additional investigations and referrals with consequent risks and costs. ${ }^{10,11}$

The Multiplex Initiative, a study launched in 2006, offered the first opportunity to use population-based health system data to test suppositions that multiplex genetic susceptibility tests (MGSTs) could result in increased health care use among those who opted to test. ${ }^{12}$ The Multiplex Initiative is a prospective observational study that offered a MGST at no cost to a

${ }^{1}$ Group Health Research Institute, Seattle, Washington; ${ }^{2}$ Social and Behavioral Research Branch, National Human Genome Research Institute, National Institutes of Health, Bethesda, Maryland; ${ }^{3}$ Henry Ford Hospital, Detroit, Michigan; ${ }^{4} \mathrm{Abt}$ Associates Inc., Bethesda, Maryland; ${ }^{5}$ Genome Technology Branch, National Human Genome Research Institute,

National Institutes of Health, Bethesda, Maryland. Correspondence: Robert J. Reid (reid.rj@ghc.org) 
population-based sample of 1,959 healthy adults aged 25-40 years. Participants were the members of a large Midwestern integrated health care system. The MGST, described elsewhere, ${ }^{13}$ was a research MGST developed for this study based on the best genetic epidemiological data available at the time. In brief, the test provided information on the presence of 15 genetic variants ("risk versions") associated with increased risk (odds ratios 1.2-2.0) for eight common health conditions (Table 1). The selected health conditions are adult-onset and deemed "preventable" in that there are widely accepted evidence-based primary and secondary prevention recommendations for these conditions. The genetic variants are prevalent $(>5 \%$ of the general population), with an average person testing positive for between 4 and 10 of the possible 15 risk versions. In this report, we compare individuals who chose testing and received results with those who chose not to test with respect to patterns of health-care use in the 12 months preceding and following the testing date. To this end, we compared number of physician visits and laboratory tests or procedures received based on automated utilization records for the tested and nontested participants.

Table 1 Conditions and gene variants included in the multiplex genetic susceptibility test

\begin{tabular}{|c|c|c|c|c|}
\hline $\begin{array}{l}\text { Health } \\
\text { condition }\end{array}$ & $\begin{array}{l}\text { Gene } \\
\text { name }\end{array}$ & $\begin{array}{c}\text { Genetic } \\
\text { variant } \\
\text { name (dbSNP } \\
\text { designation) }\end{array}$ & $\begin{array}{c}\text { Initial risk } \\
\text { estimate } \\
\text { OR }(95 \% \mathrm{Cl})\end{array}$ & Reference \\
\hline \multirow{4}{*}{$\begin{array}{l}\text { Diabetes } \\
\text { mellitus } \\
\text { (type 2) }\end{array}$} & CAPN10 & rs3792267 & $1.19(1.07-1.33)$ & 22 \\
\hline & KCNJ11 & rs5219 & $1.37(1.21-1.54)$ & 23 \\
\hline & PPARG & rs1801282 & $1.25(1.08-1.47)$ & 24 \\
\hline & TCF7L2 & rs12255372 & $1.45(1.26-1.67)$ & 25 \\
\hline \multirow[t]{3}{*}{ Osteoporosis } & COL1A1 & rs1800012 & $1.26(1.09-1.46)$ & 26 \\
\hline & ESR 1 & rs9340799 & $1.58(1.11-2.27)$ & 27 \\
\hline & IL6 & rs1800795 & $1.46(1.08-1.97)$ & 28 \\
\hline \multirow{3}{*}{$\begin{array}{l}\text { Coronary } \\
\text { heart disease }\end{array}$} & $A P O B$ & rs693 & $1.25(1.04-1.52)$ & 29 \\
\hline & CETP & rs708272 & $1.28(1.07-1.52)$ & 30 \\
\hline & NOS3 & rs1799983 & $1.31(1.13-1.51)$ & 31 \\
\hline Hyperlipidemia & LIPC & rs1800588 & $\begin{array}{c}\text { Average } \\
\text { decrease HDL } \\
0.09 \mathrm{mmol} / / \\
(0.07-0.12)\end{array}$ & 32 \\
\hline Hypertension & $A G T$ & rs699 & $1.21(1.11-1.32)$ & 33 \\
\hline Lung cancer & $M P O$ & rs2333227 & $1.47(1.08-2.0)$ & 34 \\
\hline $\begin{array}{l}\text { Colorectal } \\
\text { cancer }\end{array}$ & MTHFR & rs1801133 & $1.21(1.07-1.39)$ & 35 \\
\hline \multirow{5}{*}{$\begin{array}{l}\text { Melanoma } \\
\text { skin cancer }\end{array}$} & \multirow[t]{5}{*}{$M C 1 R$} & rs1805006 & $2.0(1.6-2.6)$ & 36 \\
\hline & & rs11547464 & & \\
\hline & & rs1805007 & & \\
\hline & & rs1805008 & & \\
\hline & & rs1805009 & & \\
\hline
\end{tabular}

$\mathrm{Cl}$, confidence interval, dbSNP, single-nucleotide polymorphism database; HDL, high-density lipoprotein; OR, odds ratio.

\section{METHODS}

Participants were recruited from the Henry Ford Health System (HFHS) in Detroit, Michigan, and surveyed by telephone. Detailed methods of study recruitment are described elsewhere. ${ }^{14}$ In brief, we randomly sampled 6,348 healthy, young adults aged 25-40 years who were commercially insured by the HFHS health maintenance plan (Health Alliance Plan) and who received care from a HFHS primary-care physician. Individuals were ineligible if they had a personal history of the diseases included on the MGST (diabetes, coronary heart disease, osteoporosis, colorectal cancer, lung cancer, or nonmelanoma skin cancer). Automated inpatient and outpatient records were prescreened and those with International Classification of Diseases Version 9 diagnoses indicative of these conditions were excluded from the sample. To achieve adequate representation of groups historically underrepresented in genetic testing research, we oversampled males, African Americans, and persons living in neighborhoods with proportionately low education levels as indicated by the most recent US census data.

Using health plan contact information, potential participants were mailed an introductory letter and then called to complete a baseline survey. The survey included screening questions to exclude the target health conditions and other criteria (e.g., intention for health plan disenrollment). After completing the interview, participants were mailed a study brochure and invited to review information on the study website about multiplex genetic testing (https://multiplex.nih.gov/).

The website included educational information on the MGST, specifics about the genes of interest (including their prevalence and risks), and four supplemental questionnaires. Incentives (in the form of gift certificates to a major retailer) were offered for completing each assessment on the website. The final assessment was simply one question: "Are you interested in genetic testing?" Participants who answered "yes" or "maybe" were contacted by a research educator to answer any additional questions and to schedule a clinic visit for blood collection. Multiple HFHS clinics throughout metropolitan Detroit served as sites for participants to provide written informed consent and blood samples. DNA was purified from blood in the DNA Diagnostic Lab at HFHS. Genotype assays were carried out at the Center for Inherited Disease Research at The Johns Hopkins University, and duplicate samples were tested at a commercial laboratory (Bioserve). The testing labs used different genotyping methods and concordant results were obtained from both labs. The distribution of genotypes of the persons tested in this study was similar to that of expected on the basis of population prevalence estimates. All participating laboratories were Clinical Laboratory Improvement Amendments-certified to carry out DNA-based tests. Personalized genetic test results were returned to participants by registered mail. A research educator phoned each participant to explain the results and answer questions. Institutional review boards of the National Institutes of Health and HFHS approved all aspects of this study.

For this analysis, two categories of health-services use were assessed: in-person visits to physicians (primary care and 
specialist physicians) and the use of laboratory tests or procedures that would likely be associated with four of the eight MGST conditions, including type 2 diabetes mellitus, atherosclerotic coronary heart disease, colorectal cancer, and lung cancer. Data for other screening tests (e.g., blood pressure measurements and visual skin cancer screenings) were not available to the study team. To that end, the data extracted for tests and procedures included fasting plasma glucose, glycated hemoglobin, and oral glucose tolerance tests (diabetes); electrocardiograms, cholesterol panels, and C-reactive protein tests (coronary heart disease); fecal occult blood tests, flexible sigmoidoscopies, and colonoscopies (colorectal cancer); and chest $\mathrm{x}$-rays and computerized tomography (lung cancer). With the exception of cholesterol testing for males (beginning at age 35), none of these are recommended screenings by the US Preventive Services Taskforce for average-risk individuals in this age group. Physician visits were measured as both a binary (any visits-yes, no) and continuous (visit counts) outcome. Laboratory and procedure data for each condition were analyzed only as a binary outcome (any lab/procedure-yes, no). As expected, few of these tests and procedures were performed in this young, healthy population, precluding their analysis as a continuous outcome.

Use of services was compared between three mutually exclusive participant groups: (i) participants who completed the baseline telephone survey only ("baseline-only"), (ii) participants who completed the survey, visited the study website, and completed the additional assessments but who chose not to be

Table 2 Baseline demographics

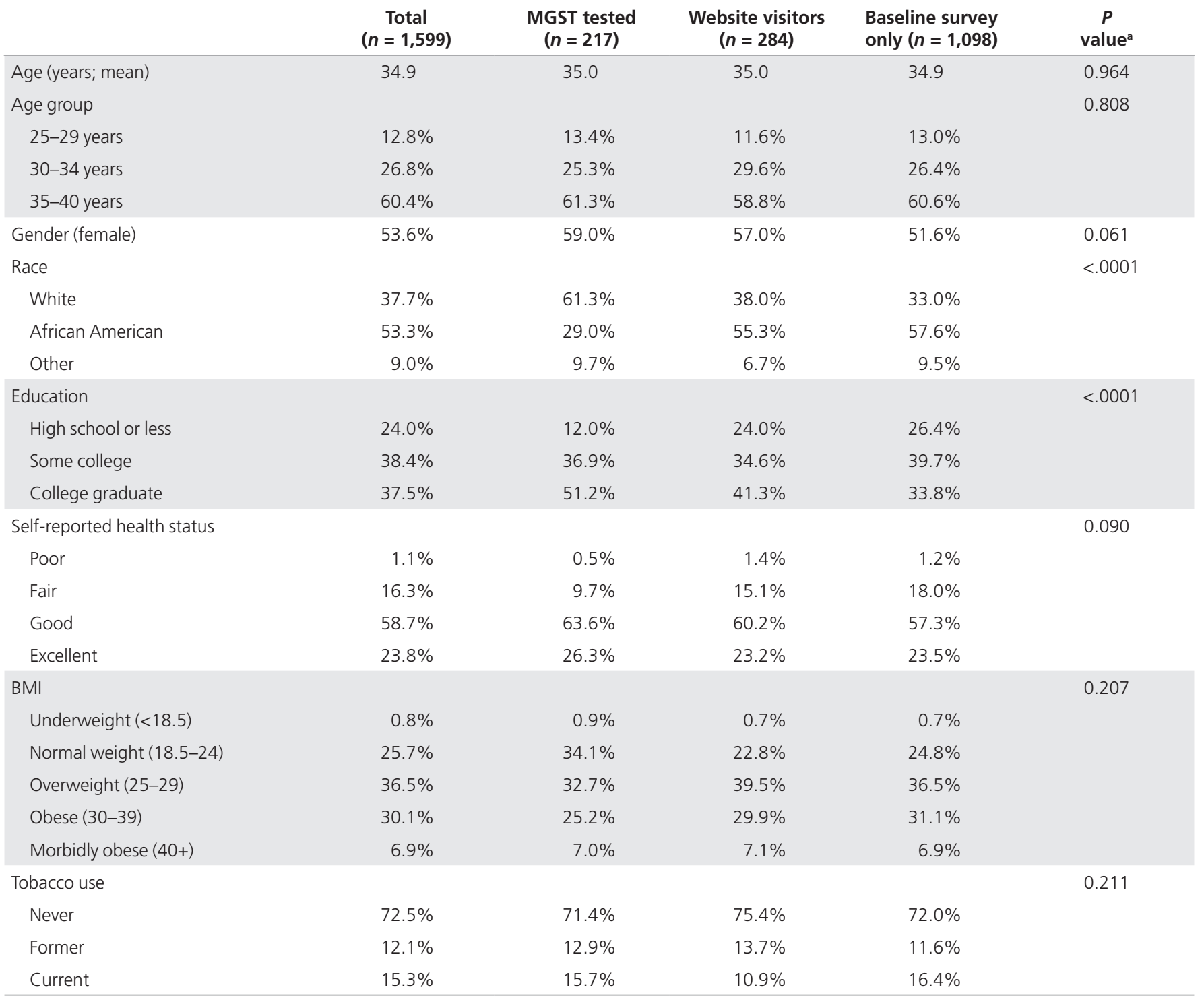

BMI, body mass index; MGST, multiplex genetic susceptibility test.

a $P$ value for test of whether baseline demographics vary between the three groups (MGST tested, website visitors, or baseline survey only). For age, continuous test is from one-way analysis of variance. For other demographic characteristics, tests are $\chi^{2}$ tests of independence. 
tested ("Web-only"), and (iii) those who completed the latter steps and ultimately obtained the MGST. For "MGST testers," use data were extracted from automated records for the 12 months before and the 12 months after the testing date (ranging from February 2006 to November 2009). For the baseline-only and Web-only groups, a comparable index date was calculated by applying the average duration between baseline interview and genetic testing for the MGST testers. Use data were then similarly extracted for the 12 months before and the 12 months after this index date. The health-care data were aggregated into quarterly intervals in the periods before and after the testing (or index) date. For this analysis, subjects were excluded if they were not continuously enrolled for the entire 24-month period (defined as having no enrollment gaps greater than 90 days).

The quarterly use data were analyzed using two-level hierarchical linear models where repeated observations on individuals (level 1) were nested within individuals (level 2). Eight observations were included for each subject, for each of the four quarters before (pretest) and after (posttest) the test (or index) date. The analysis models included random intercepts for individuals and a random effect for the posttest period. We tested for pretest use differences among the three participant groups, and for differences among the groups in use changes from preto posttest. When the latter test indicated no significant amonggroup differences, an additional model was fitted to test whether use, for the whole sample combined, significantly changed from pre- to posttest. The second model was of the same form as the first but dropped a term for the interaction between groups and the indicator for posttest period; hence, this model produced an estimate of the main effect contrasting use in the posttest versus pretest periods. The following variables were tested for inclusion as covariates in the analysis models: age, sex, race, education level, self-reported health status, smoking status, body mass index, and season. For dependent variables, the covariate selection process began with a model that included all covariates, and covariates with $P$ values $>0.20$ were successively dropped and models re-estimated, as described by others. ${ }^{15,16}$ This procedure was performed until all remaining covariates had $P$ values $<0.20$. The sample size enabled us to detect between-group differences in utilization of $7-8 \%$ for any physician visits in a quarter, $4-5 \%$ for specialist and well-care visits, and $2-6 \%$ for use of laboratory tests with $80 \%$ power.

\section{RESULTS}

\section{Sample characteristics}

Of the 6,348 individuals prescreened and with available health plan contact information, 1,509 did not have valid telephone numbers, 1,105 were unreachable despite repeated attempts, 326 were ineligible because of age, language, and distance barriers, 1,292 declined to participate, and 2,116 completed the baseline interview. All participants in this analysis were continuously enrolled in the Health Alliance Plan for the 24-month period of observation. Comparisons of survey respondents and nonrespondents are presented elsewhere. ${ }^{14}$ In brief, men were less likely than women ( 29 vs. $39 \%$ ), African Americans were less likely than Caucasians (33 vs. 36\%), and persons from lower education neighborhoods were less likely than those from other neighborhoods (32 vs. $35 \%$ ) to complete the baseline survey. For this analysis, 157 respondents were excluded because they reported having a health condition of the MGST, and 360 for interruptions in health-care insurance; this resulted in a final sample of 1,599 individuals.

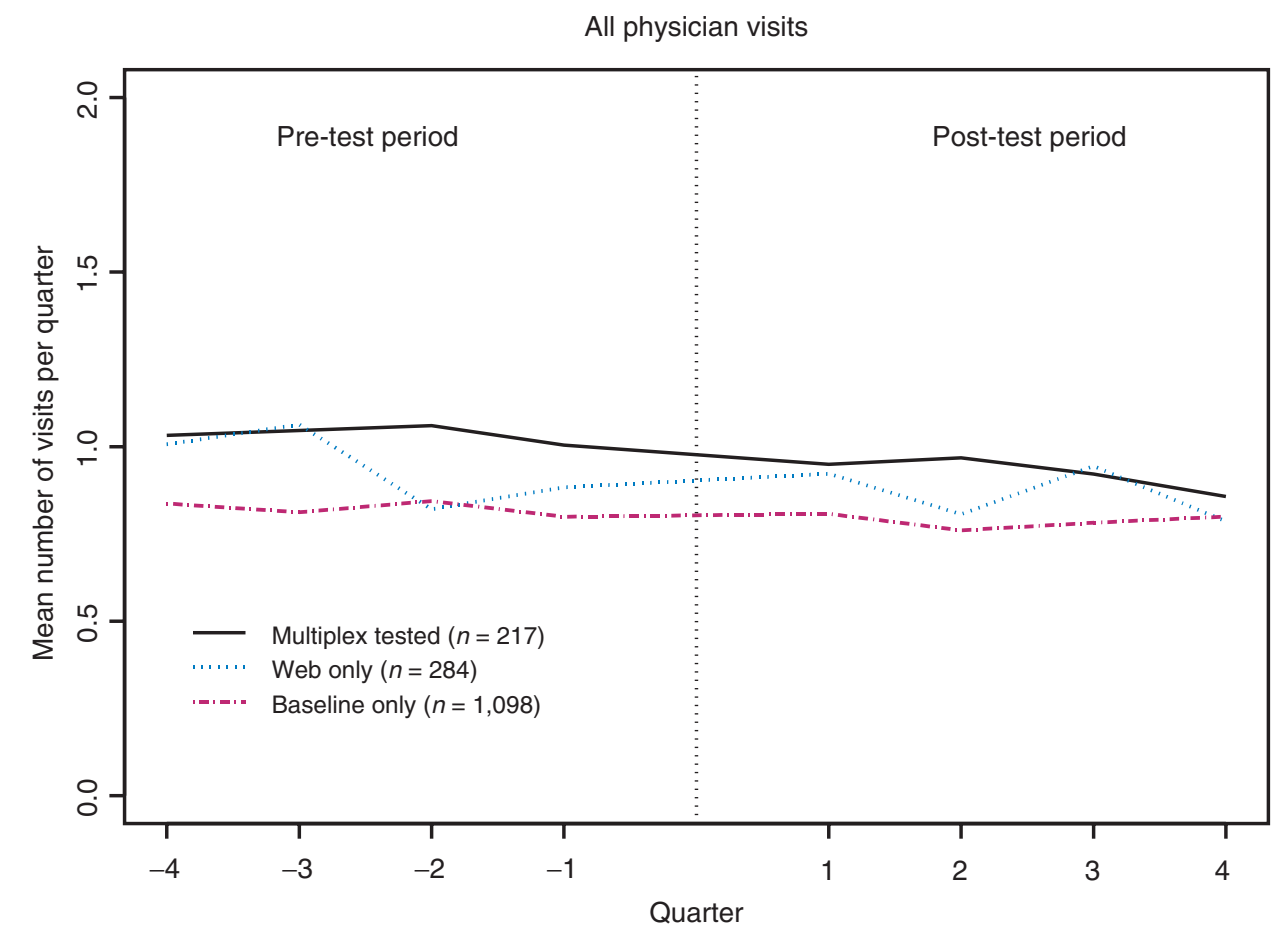

Figure 1 Utilization trends of all physician visits over time and by multiplex genetic susceptibility test testing status group. 
Table 2 compares the baseline demographic, health status, and behavioral characteristics of the 1,098 subjects (68.7\%) who completed the baseline survey only, the 284 (17.8\%) who visited the study website at least once but who did not choose the MGST, and the 217 (13.6\%) who chose to be tested. As we previously reported, ${ }^{14,17}$ African Americans were significantly less likely than whites to choose testing, as were participants with high school education or less. No significant differences were found among the study groups with regard to age, gender, self-reported health status, body mass index, or tobacco use, all factors associated with health-care use.

The health-care use analyses were based on 12,792 personquarters of data. The unadjusted analyses of total physician visits suggested declining patterns of use over this period but with no large differences among the three groups (Figure 1). After accounting for within-person clustering and adjusting for differences in age, sex, self-reported health, and body mass index at baseline, the percentages of persons who had at least one physician visit in a quarter, averaged across the quarters in the pretest period, were $41.3,43.7$, and $46.7 \%$ respectively, for the baselineonly, the Web-only and the MGST tested groups (Table 3 ). The MGST tested group had significantly greater pretest physician visits than did the baseline-only group $(P=0.018)$ but did not have significantly greater pre-test utilization than the Web-only group $(P=0.28)$. Similarly, when counts per quarter were examined, small but statistically significant differences among the groups were observed. In the pretest period, the MGST tested group had a model-adjusted average of 1.02 physician visits per quarter, whereas the baseline-only and Web-only groups had averages of 0.93 and 0.82 visits, respectively $(P=0.011)$. Again, the MGST tested group had a significantly greater number of pretest physician visits than the baseline-only group $(P=0.006)$ but not the Web-only group $(P=0.30)$.

For primary-care visits in the pretest period, no significant differences among groups were found in either the percentage of persons making a visit or the number of visits made. However, for specialist care, the MGST tested group was more likely to have made a visit than the baseline-only group (11.8 vs. $8.2 \%, P=0.009)$ and used significantly more visits per quarter ( 0.18 vs. $0.11, P<0.001)$. For laboratory tests and procedures, there were no significant differences among the three groups.

Analysis of changes in use between the pre- and posttest periods indicated significant declines in the adjusted use of physician visits across all participants. From the pretest to the

Table 3 Adjusted utilization in pretest period by MGST testing status repeated-measures HLM regression

\begin{tabular}{|c|c|c|c|c|c|c|}
\hline \multirow[b]{2}{*}{ Utilization per quarter } & \multicolumn{3}{|c|}{ Mean utilization in pretest period } & \multirow[b]{2}{*}{$\begin{array}{c}P \text { value } \\
\text { difference } \\
\text { among } \\
\text { groups }^{\text {d }}\end{array}$} & \multirow[b]{2}{*}{$\begin{array}{c}\text { P value } \\
\text { MGST } \\
\text { vs. baseline }\end{array}$} & \multirow[b]{2}{*}{$\begin{array}{c}P \text { value } \\
\text { MGST } \\
\text { vs. web }\end{array}$} \\
\hline & $\begin{array}{c}\text { MGST } \\
\text { testers }^{\mathrm{a}}\end{array}$ & $\begin{array}{l}\text { Web } \\
\text { only }^{b}\end{array}$ & $\begin{array}{l}\text { Baseline } \\
\text { only }^{c}\end{array}$ & & & \\
\hline \multicolumn{7}{|c|}{ Percentage with any physician visits in quarter } \\
\hline All physicians & $46.7 \%$ & $43.7 \%$ & $41.3 \%$ & $0.046^{*}$ & $0.018^{*}$ & 0.281 \\
\hline Well-care visits & $16.1 \%$ & $12.8 \%$ & $12.3 \%$ & $0.021 *$ & $0.005^{* *}$ & $0.042^{*}$ \\
\hline \multicolumn{7}{|c|}{ Number of physician visits in quarter } \\
\hline All physicians & 1.02 & 0.93 & 0.82 & $0.011^{*}$ & $0.006 * *$ & 0.300 \\
\hline Primary-care physicians & 0.81 & 0.74 & 0.69 & 0.108 & $0.046^{*}$ & 0.375 \\
\hline Diabetes & $1.2 \%$ & $1.3 \%$ & $1.4 \%$ & 0.950 & 0.749 & 0.823 \\
\hline Coronary heart disease & $11.0 \%$ & $11.0 \%$ & $10.0 \%$ & 0.501 & 0.396 & 0.997 \\
\hline Lung cancer & $3.4 \%$ & $3.0 \%$ & $2.7 \%$ & 0.525 & 0.284 & 0.635 \\
\hline Any of above & $13.1 \%$ & $13.6 \%$ & $12.4 \%$ & 0.528 & 0.599 & 0.721 \\
\hline
\end{tabular}

Data were analyzed using two-level hierarchical linear models. The analytic models included random intercepts for individuals and a random effect for posttest period. For each model the following outcomes were tested for inclusion as control covariates: age, sex, race, education level, self-perceived health status, smoking status, BMI, and season.

BMI, body mass index; HLM, hierarchical linear model; MGST, multiplex genetic susceptibility test.

aModel-adjusted mean calculated by adding the model-adjusted pretest difference between MGST testers and baseline-only group to the unadjusted mean of the baselineonly group. 'bodel adjusted mean calculated by adding the model-adjusted pretest difference between Web-only and baseline-only groups to the unadjusted mean of the baseline-only group. CUnadjusted mean per quarter utilization for the pretest period. ' ${ }^{T}$ Test of equality of pretest utilization means for MGST testers, Web-only, and baselineonly groups. 'Test of equality of pretest utilization means for MGST testers and baseline-only groups; results reported only if overall test of equality of means among the three groups was rejected using $P<0.05$ criterion. 'Test of equality of pretest utilization means for the MGST testers and Web-only groups; results reported only if overall test of equality of means among the three groups was rejected using $P<0.05$ criterion. ${ }^{\star} P<0.05$; ${ }^{*} P<0.01$. 
posttest period, the percentage of individuals who had a physician visit per quarter declined by $1.8 \%(P=0.027)$ and the mean number of physician visits per quarter declined by 0.05 visits per quarter $(P=0.047)$ across all groups. When changes in utilization were compared among the study groups, however, no statistically significant differences were observed for any of the utilization categories (Table 4).

\section{DISCUSSION}

This study is the first to employ automated health service records rather than individual self-report ${ }^{9}$ to measure the impact of offering multiplex genetic susceptibility testing on the use of health services among healthy commercially insured adults. We found no changes in overall use of health care among those receiving personalized genetic test results as compared with those who were not tested, as indicated by visits to physicians, specialists, procedures, or screening tests, the majority of which are not currently recommended for asymptomatic screening in this age group. Although our findings may reassure policy makers interested in constraining costs, they may reveal a best-case scenario reflective of the insured population we studied and the approach we took. Our MGST included a small subset of traits where the risks conferred by the genes on the test were relatively small and potentially actionable. This contrasts to the large array of traits, ranging from medically inconsequential to potentially life-threatening, that are typical of direct-to-consumer company offerings. ${ }^{18}$ We also provided detailed written and oral information about the uncertain clinical implications of these tests with patients and did not directly encourage them to consult their physicians. This may have decreased demand for interpretation by clinicians. Our finding that MGST testers had greater use of physician services before testing, particularly specialist services, deserves further study. It may be that persons who choose genetic testing have a greater propensity to use services in general, or that they become more sensitized to the influence of genetics in their greater interactions with physicians.

These results lead us to tentatively suggest that offering MGST testing to a young, healthy population would not increase use of health care. However, going forward, the rapid pace of genomic advances and shifts in their readiness for application in clinical practice could lead to genetic test offerings with impact on health-care use that was not measured in our study. Another idiosyncrasy of our study design to consider is that subjects in this study were offered the multiplex genetic susceptibility test at no charge. We provided the test at no cost and it may be that cost-sharing may motivate some people to seek health-care as a result of the findings. Yet, despite the general enthusiasm in the scientific and popular press about the potential of personalized medicine and genetic susceptibility testing, ${ }^{19,20}$ there was generally little interest in this testing among our sample, even when provided at no charge.

In addition, our study did not explore patterns of use among subgroups of the MGST testers. Changes may have existed for

Table 4 Adjusted pretest to posttest change in utilization by MGST testing status

\begin{tabular}{|c|c|c|c|c|}
\hline \multirow[b]{2}{*}{ Utilization measure } & \multicolumn{3}{|c|}{ Change in utilization from pretest to posttest } & \multirow[b]{2}{*}{$\begin{array}{l}P \text { value difference } \\
\text { among groups }^{b}\end{array}$} \\
\hline & $\begin{array}{l}\text { MGST } \\
\text { testers }^{\mathrm{a}}\end{array}$ & $\begin{array}{l}\text { Web } \\
\text { only }\end{array}$ & $\begin{array}{l}\text { Baseline } \\
\text { only }^{\mathrm{a}}\end{array}$ & \\
\hline \multicolumn{5}{|c|}{ Percentage with any physician visits in quarter } \\
\hline All physicians & $-0.6 \%$ & $-0.9 \%$ & $-2.2 \%$ & 0.690 \\
\hline Primary-care physicians & $0.4 \%$ & $-1.1 \%$ & $-2.0 \%$ & 0.587 \\
\hline Specialists & $-1.3 \%$ & $-0.8 \%$ & $-0.6 \%$ & 0.860 \\
\hline \multicolumn{5}{|c|}{ Number of physician visits in quarter } \\
\hline All physicians & -0.10 & -0.08 & -0.04 & 0.608 \\
\hline Primary-care physicians & -0.04 & -0.05 & -0.02 & 0.863 \\
\hline Specialists & -0.05 & -0.03 & -0.01 & 0.115 \\
\hline \multicolumn{5}{|c|}{ Percentage with laboratory test or procedure in quarter } \\
\hline Coronary heart disease & $0.0 \%$ & $0.2 \%$ & $0.9 \%$ & 0.789 \\
\hline Lung cancer & $-0.1 \%$ & $-0.2 \%$ & $-0.3 \%$ & 0.977 \\
\hline Any of above & $2.3 \%$ & $0.5 \%$ & $0.9 \%$ & 0.660 \\
\hline
\end{tabular}

Data were analyzed using two-level hierarchical linear models. The analytic models included random intercepts for individuals and a random effect for posttest period. For each model the following outcomes were tested for inclusion as control covariates: age, sex, race, education level, self-perceived health status, smoking status, BMI, and season.

BMI, body mass index; MGST, multiplex genetic susceptibility test.

${ }^{a}$ Model-adjusted mean change in per-quarter utilization from pretest to posttest. Negative values imply lower utilization in posttest period. ${ }^{b}$ Test of equality of mean change in utilization for the MGST tester, Web-only, and baseline-only groups. 
tested individuals with fewer versus greater at-risk variants. In our study, all study participants carried at least one at-risk genetic marker, and the majority of participants carried multiple risks, on average receiving nine risk variants. Our sample size and low patterns of health-care use precluded these post hoc comparisons. We also did not review medical records to examine whether test results were discussed with physicians in the context of other visits, or explore the counseling demands placed on physicians and other clinical staff. Our data also precluded the differentiation between appropriate and inappropriate use by the study subjects, or changes in utilization beyond 12 months. Answers to these questions are needed before fully understanding the health system implications of MGSTs instigated and delivered outside the context of usual care.

To date, this report is the first to characterize the potential impact of genetic susceptibility testing provided via a direct-toconsumer approach on objective indicators of health utilization. As has been called for by others, ${ }^{21}$ considerations of the impact on health-care systems will continue to be paramount if we are to effectively and efficiently integrate new genomic discoveries into clinical care. To be of true benefit, these new genomic products should neither inappropriately increase health-care costs nor amplify health disparities.

\section{ACKNOWLEDGMENTS}

Robert Reid had full access to all of the data in the study and takes responsibility for the integrity of the data and the accuracy of the data analysis. This work was supported by the Intramural Research Program of the National Human Genome Research Institute (NHGRI), National Institutes of Health $(\mathrm{NIH})$. The research was also made possible by collaboration with the Cancer Research Network funded by the National Cancer Institute (U19 CA 079689). Additional resources were provided by the Group Health Research Institute (GHRI) and Henry Ford Hospital (HFH). Genotyping services were provided by the Center for Inherited Disease Research, which is fully funded through a federal contract from the NIH to The Johns Hopkins University (HHSN268200782096C). We are indebted to G. Gibney, D. Kanney, M. Fredriksen, D. Leja, and C. Wade at NHGRI; S. Anteau, H. Kromei, E. Hasiec, N. Maddy, and K. Wells at HFH, and C. Wiese, and R. Pardee at GHRI for their assistance. We also acknowledge A. Parsad and R. Subramanian from Abt Associates, who assisted with the statistical analyses. Finally, we extend our deepest thanks to all of the HFHS study participants.

\section{DISCLOSURE}

The authors declare no conflict of interest.

\section{REFERENCES}

1. Evans JP, Dale DC, Fomous C. Preparing for a consumer-driven genomic age. N Engl J Med. 2010;363:1099-1103.

2. Ashley EA, Butte AJ, Wheeler MT, et al. Clinical assessment incorporating a personal genome. Lancet 2010;375:1525-1535.

3. Feero WG, Guttmacher AE, Collins FS. Genomic medicine-an updated primer. NEng/ J Med 2010;362:2001-2011.

4. Annes JP, Giovanni MA, Murray MF. Risks of presymptomatic direct-toconsumer genetic testing. N Engl J Med 2010;363:1100-1101.
5. Kravitz RL, Bell RA, Azari R, Kelly-Reif S, Krupat E, Thom DH. Direct observation of requests for clinical services in office practice: what do patients want and do they get it? Arch Intern Med 2003;163:1673-1681.

6. Keitz SA, Stechuchak KM, Grambow SC, Koropchak CM, Tulsky JA. Behind closed doors: management of patient expectations in primary care practices. Arch Intern Med 2007; 167:445-452.

7. Mintzes B, Barer ML, Kravitz RL, et al. How does direct-to-consumer advertising (DTCA) affect prescribing? A survey in primary care environments with and without legal DTCA. CMAJ 2003;169:405-412.

8. McGuire AL, Diaz CM, Wang T, Hilsenbeck SG. Social networkers' attitudes toward direct-to-consumer personal genome testing. Am J Bioeth 2009;9:3-10.

9. Bloss CS, Schork NJ, Topol EJ. Effect of direct-to-consumer genomewide profiling to assess disease risk. N Eng/ J Med 2011;364:524-534.

10. McGuire AL, Burke W. An unwelcome side effect of direct-to-consumer personal genome testing: raiding the medical commons. JAMA 2008;300:2669-2671.

11. Caulfield T, Ries NM, Ray PN, Shuman C, Wilson B. Direct-to-consumer genetic testing: good, bad or benign? Clin Genet 2010;77:101-105.

12. McBride CM, Alford SH, Reid RJ, Larson EB, Baxevanis AD, Brody LC. Putting science over supposition in the arena of personalized genomics. Nat Genet 2008:40:939-942.

13. Wade CH, McBride CM, Kardia SL, Brody LC. Considerations for designing a prototype genetic test for use in translational research. Public Health Genomics 2010;13:155-165.

14. Hensley Alford S, McBride CM, Reid RJ, Larson EB, Baxevanis AD, Brody LC. Participation in genetic testing research varies by social group. Public Health Genomics 2011;14:85-93.

15. Budtz-Jørgensen E, Keiding N, Grandjean P, Weihe P. Confounder selection in environmental epidemiology: assessment of health effects of prenatal mercury exposure. Ann Epidemiol 2007;17:27-35.

16. Maldonado G, Greenland S. Simulation study of confounder-selection strategies. Am J Epidemio/ 1993;138:923-936.

17. McBride CM, Alford SH, Reid RJ, Larson EB, Baxevanis AD, Brody LC. Characteristics of users of online personalized genomic risk assessments: implications for physician-patient interactions. Genet Med 2009;11: 582-587.

18. Udesky L. The ethics of direct-to-consumer genetic testing. Lancet 2010;376:1377-1378.

19. Feero WG, Guttmacher $A E$, Collins FS. The genome gets personal-almost. JAMA 2008;299:1351-1352.

20. McCarthy MI, Abecasis GR, Cardon LR, et al. Genome-wide association studies for complex traits: consensus, uncertainty and challenges. Nat Rev Genet 2008;9:356-369.

21. Scheuner MT, Sieverding P, Shekelle PG. Delivery of genomic medicine for common chronic adult diseases: a systematic review. JAMA 2008;299: 1320-1334.

22. Song Y, Niu T, Manson JE, Kwiatkowski DJ, Liu S. Are variants in the CAPN10 gene related to risk of type 2 diabetes? A quantitative assessment of population and family-based association studies. Am J Hum Genet 2004;74:208-222.

23. Florez JC, Sjögren M, Burtt N, et al. Association testing in 9,000 people fails to confirm the association of the insulin receptor substrate- 1 G972R polymorphism with type 2 diabetes. Diabetes 2004;53: 3313-3318.

24. Altshuler D, Hirschhorn JN, Klannemark M, et al. The common PPARgamma Pro12Ala polymorphism is associated with decreased risk of type 2 diabetes. Nat Genet 2000;26:76-80.

25. Grant SF, Thorleifsson G, Reynisdottir I, et al. Variant of transcription factor 7-like 2 (TCF7L2) gene confers risk of type 2 diabetes. Nat Genet 2006;38:320-323.

26. Mann V, Ralston SH. Meta-analysis of COL1A1 Sp1 polymorphism in relation to bone mineral density and osteoporotic fracture. Bone 2003;32: 711-717.

27. Ioannidis JP, Stavrou I, Trikalinos TA, et al. Association of polymorphisms of the estrogen receptor alpha gene with bone mineral density and fracture risk in women: a meta-analysis. J Bone Miner Res 2002;17:20482060.

28. Nordström A, Gerdhem P, Brändström H, et al. Interleukin-6 promoter polymorphism is associated with bone quality assessed by calcaneus 
ultrasound and previous fractures in a cohort of 75-year-old women. Osteoporos Int 2004; 15:820-826.

29. Boekholdt SM, Peters RJ, Fountoulaki K, Kastelein JJ, Sijbrands EJ. Molecular variation at the apolipoprotein $B$ gene locus in relation to lipids and cardiovascular disease: a systematic meta-analysis. Hum Genet 2003;113:417-425.

30. Boekholdt SM, Sacks FM, Jukema JW, et al. Cholesteryl ester transfer protein TaqIB variant, high-density lipoprotein cholesterol levels, cardiovascular risk, and efficacy of pravastatin treatment: individual patient meta-analysis of 13,677 subjects. Circulation 2005;111:278-287.

31. Casas JP, Bautista LE, Humphries SE, Hingorani AD. Endothelial nitric oxide synthase genotype and ischemic heart disease: meta-analysis of 26 studies involving 23028 subjects. Circulation 2004;109:1359-1365.

32. Isaacs A, Sayed-Tabatabaei FA, Njajou OT, Witteman JC, van Duijn CM. The -514 C->T hepatic lipase promoter region polymorphism and plasma lipids: a meta-analysis. J Clin Endocrinol Metab 2004;89:3858-3863.

33. Mondry A, Loh M, Liu P, Zhu AL, Nagel M. Polymorphisms of the insertion / deletion ACE and M235T AGT genes and hypertension: surprising new findings and meta-analysis of data. BMC Nephrol 2005;6:1.

34. Feyler A, Voho A, Bouchardy C, et al. Point: myeloperoxidase -463G $\rightarrow$ a polymorphism and lung cancer risk. Cancer Epidemiol Biomarkers Prev 2002;11:1550-1554.

35. Kim DH, Ahn YO, Lee BH, Tsuji E, Kiyohara C, Kono S. Methylenetetrahydrofolate reductase polymorphism, alcohol intake, and risks of colon and rectal cancers in Korea. Cancer Lett 2004;216:199-205.

36. Palmer JS, Duffy DL, Box NF, et al. Melanocortin-1 receptor polymorphisms and risk of melanoma: is the association explained solely by pigmentation phenotype? Am J Hum Genet 2000;66: 176-186. 